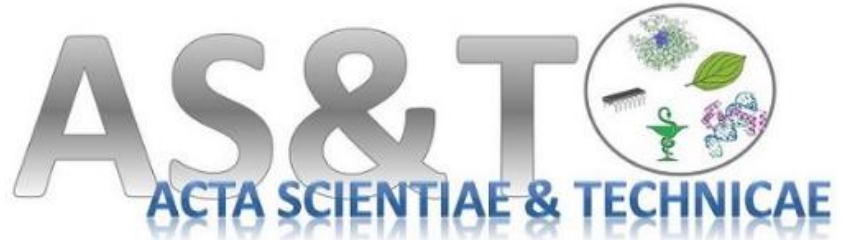

\section{Marcas negadas por ofenderem a moral e os bons costumes} Anderson Moraes de Castro e Silva ${ }^{1} \&$ Carlos Maurício Pires e Albuquerque Ardissone ${ }^{2}$

\section{AUTHOR AFILIATIONS}

1 - Fundação Centro Universitário

Estadual da Zona Oeste

2 - Instituto Nacional de

Propriedade Intelectual

\section{CONTACT}

guaratibano@gmail.com

\begin{abstract}
The article aims to unveil aspects of the conception of morality that guides the administrative investigation of registration of trademark applications by the examiners of the National Institute of Industrial Property (INPI). In particular, we are interested in the signals that were rejected because they were classified as offensive to morals and good customs. But what morality is that? In a survey, conducted in the database used by the INPI servers, referring to applications for trademark registrations required from September 1987 to October 2009, we found 360 cases of trademarks that were denied because they were classified as infringing the law. From the study of this material, we wrote this paper in an attempt to map the factors that motivated the rejection of these trademarks. Finally, we point out aspects of hegemonic moral standard that underlies the administrative analysis, collected in the field.
\end{abstract}

Keywords: trademark, morality, INPI.

\section{RESUMO}

$\mathrm{O}$ artigo objetiva identificar aspectos da concepção de moralidade que orienta o procedimento administrativo de exame dos pedidos de registro de marcas pelos analistas do INPI. Em especial, nos interessam os sinais que foram indeferidos por terem sido classificados como ofensivos à moral e aos bons costumes. Neste sentido, o cerne da análise se volta para os casos em que os pedidos de registro foram negados com base inciso III, do art. 124, da Lei de Propriedade Industrial, que fixa que não são registráveis como marca "Expressão, figura, desenho ou qualquer outro sinal contrário à moral e aos bons costumes ou que ofenda a honra ou a imagem de pessoas ou atente contra liberdade de consciência, crença, culto religioso ou ideia e sentimento dignos de respeito e veneração". Mas que moralidade é essa? Em levantamento efetuado no banco de dados do Instituto Nacional da Propriedade Industrial (INPI), referentes a pedidos de registros de marcas depositados entre setembro de 1987 a outubro de 2009, encontramos 360 casos de marcas que foram negadas por terem sido classificadas como infringentes ao inciso supracitado. A partir do estudo desse material, estruturamos o presente texto na tentativa de mapear os fatores que influenciam nas decisões denegatórias dos examinadores de marcas. O resultado pretendido será o de identificar se há, 
nos dados coletados, um padrão moral subjacente às decisões da instituição, tomadas por suas duas instâncias administrativas.

Palavras-chave: marca registrada, moralidade, INPI.

\section{INTRODUÇÃO}

São muitas as controvérsias a respeito do surgimento das primeiras marcas. Autores como ARNOLDI E ADOURIAN (2003, p. 226) afirmam que a origem das marcas remonta à Antiguidade e que, já na época romana, elas eram usadas para identificar rebanhos de animais entre seus diferentes donos. Mas teria sido na Idade Média que as marcas se aperfeiçoaram como instrumentos de identificação de produtos. As corporações, àquela época, utilizavam marcas para identificar seus produtos entre os demais, indicando a sua procedência e vinculando-o assim a uma qualidade a ser aferida pelo público comprador. De acordo com SOARES (2003, p. 9), na Idade Média a marca passa a ser aplicada aos mais variados objetos rudimentarmente manufaturados e a ter a característica de designar os produtos, como sinal distintivo.
Foi com o advento da Revolução Industrial e o desenvolvimento do sistema capitalista que as marcas adquiriram maior projeção. As oficinas pertencentes às antigas corporações deram lugar às fábricas e, após, aos grandes conglomerados industriais. O incremento da produção gerou um acirramento da concorrência e, assim, fortaleceu-se a função econômica das marcas não só como diferenciadoras de produtos, mas também como elemento de competitividade mercadológica, tal como acontece atualmente. NUNES (2003) demonstra que, nos tempos de globalização econômica, as empresas estão cada vez mais atentas para os benefícios de uma marca forte. É tarefa complexa mensurar os valores de suas marcas, em termos de "ativos intangíveis", apesar das grandes empresas já disporem de meios contábeis para fazê-lo. Em alguns casos, o valor 
da marca pode responder por mais de $90 \%$ do valor de mercado de uma empresa.

O vulto econômico que as marcas atingiram, nos dias de hoje, como ativos intangíveis das empresas, não escapou a alguns estudos mais críticos do processo de globalização econômica. ${ }^{1}$ Coloca-se até que ponto não se estaria vivendo sob uma espécie de "ditadura das marcas", uma vez que para os poucos empresários dos países em desenvolvimento com fôlego exportador estaria cada vez mais difícil difundir e triunfar com sua marca em um mundo em que os escopos de proteção se ampliam cada vez mais em escala global a favor dos maiores detentores de marca no mundo: as grandes corporações transnacionais.

Independentemente da posição que se assuma nesse debate, o fato é que poucos se arriscam a negar a importância que as marcas assumiram na economia internacional. Afinal, foi por intermédio delas que empresários e empresas logram identificar seus produtos e serviços no mercado e se diferenciar de seus concorrentes.

\footnotetext{
${ }^{1}$ Ver o livro de Klein (2002), Sem Logo. A Tirania das Marcas em um Planeta Vendido.
}

O que é uma marca? As marcas podem ser definidas como "todo sinal distintivo aposto facultativamente aos produtos e serviços, para identificá-los e diferenciá-los” (DE OLIVEIRA, 1996, p. 1). Existem diferenças básicas entre as definições doutrinária e legal. De fato, do ponto de vista da doutrina, as marcas são entendidas sob um prisma amplo, vinculadas ao mercado consumidor e à possibilidade de distinguir os produtos ou serviços que lhe são disponibilizados. A marca seria qualquer sinal aposto a um produto ou serviço, podendo se revestir de forma gráfica, figurativa, plástica, fotográfica ou qualquer outra. Já a Lei n 9.279, de 14 de maio de 1996, também conhecida como Lei da Propriedade Industrial (ou simplesmente LPI), dispõe, em seu artigo 122, serem suscetíveis de registro como marca, no Brasil, apenas os sinais distintivos visualmente perceptíveis, não compreendidos nas proibições legais. Vê-se que o conceito do legislador é claramente restritivo, uma vez que não admite a possibilidade de registro como marca de sinais que não sejam 
visualmente perceptíveis, como são os sinais

gustativos, olfativos e sonoros. Ao mesmo tempo, estabelece também uma série de situações em que sinais não podem ser registrados como marca no Brasil, as chamadas "restrições legais". Tais vedações se encontram, em sua maioria, elencadas no artigo 124, da LPI, em 23 incisos. Entre as proibições legais, interessa-nos particularmente a prevista no inciso III do artigo 124, segundo o qual:

Art. 124. Não são registráveis como marca: $[\ldots]$

III - expressão, figura, desenho ou qualquer outro sinal contrário à moral e aos bons costumes ou que ofenda a honra ou imagem de pessoas ou atente contra a liberdade de consciência,

\footnotetext{
${ }^{2}$ De acordo com o artigo $2^{\circ}$ da Lei $n^{\circ} 5.648$, de 11 de setembro de 1970, com redação modificada pelo artigo 240 da Lei $\mathrm{n}^{\circ}$ 9.279, de 14 de maio de 1996, “O INPI tem por finalidade principal executar, no âmbito nacional, as normas que regulam a propriedade industrial, tendo em vista a sua função econômica, jurídica e técnica, bem como pronunciar-se quanto à conveniência de assinatura, ratificação e denúncia de convenções, tratados, convênios e
}

crença, culto religioso ou ideia e sentimento dignos de respeito e de veneração.

Mas quais são os sinais que não podem ser registrados como marcas por ofenderem a moral e os bons costumes? No âmbito da Administração Pública, a entidade responsável pela apreciação da registrabilidade de sinais como marcas é o Instituto Nacional da Propriedade Industrial (INPI), autarquia federal atualmente vinculada ao Ministério do Desenvolvimento, Indústria e Comércio Exterior (MDIC). ${ }^{2}$

O objetivo deste estudo consiste em buscar averiguar quais são os parâmetros de exame que levaram o INPI a indeferir pedidos de registros de marcas com base no inciso III, do artigo 124, da LPI. Qual a moralidade que informou os atos do INPI? É possível aferir, a partir das decisões examinadas, um padrão ético

acordos sobre propriedade industrial". Vale esclarecer que os direitos de propriedade intelectual decorrem do exercício da criação intelectual humana e são formados pelos direitos da propriedade industrial (essencialmente, marcas, patentes e desenhos industriais), juntamente com os direitos advindos da propriedade literária, científica e artística (direitos autorais). 
de conduta da instituição? Em caso positivo, qual seria?

Em termos de amostragem, a pesquisa, de caráter exploratório, pôde avaliar 360 pedidos de registros de marca depositados entre setembro de 1987 e outubro de 2009 e que foram indeferidos por se referirem a sinais que o INPI considerou contrários à moral e os bons costumes. Alguns deles (31 pedidos) foram submetidos à apreciação da instância recursal da autarquia que, em alguns casos (18), optou por manter a decisão da Diretoria e, em outros (13), reformou a decisão, por considerar que não se tratavam de marcas imorais e que feriam os bons costumes. Todas as decisões foram objeto de interesse da pesquisa, particularmente aquelas em que houve mudança de entendimento. Não obstante, foi necessário destacar algumas decisões em detrimento de outras, dada a impossibilidade de tratar, no espaço deste artigo, de todos os casos.

Esclarece-se que não se conjuga com os propósitos deste artigo realizar um exame das bases conceituais que informam, ao longo de séculos e por intermédio de inúmeros autores clássicos e contemporâneos relevantes, a discussão sobre moral, ética e valores no campo da Filosofia, do Direito e de ciências afins. Reconhece-se, contudo, imensas possibilidades analíticas decorrentes dessa trilha teórica para pesquisas futuras.

Este trabalho está organizado em mais três partes, além desta Introdução. A primeira discute a experiência de escritórios nacionais de propriedade intelectual de outros países na aplicação de normas análogas ao inciso III do artigo 124, da LPI, em suas legislações. Destacase o caso dos Estados Unidos da América pela vasta experiência e riqueza de fontes a respeito do tema. Após, ingressa-se no estudo de caso, com a análise das decisões do INPI que indeferiram pedidos de registros de marca com fulcro no inciso III, artigo 124, da LPI. Finalmente, apresentam-se considerações finais.

\section{I - Marcas Imorais e Escandalosas nas}

Legislações de Propriedade Intelectual: a experiência dos EUA

A primeira legislação de que se tem notícia a respeito das marcas atentatórias à moral, aos bons costumes e aos sentimentos dignos de 
veneração foi a lei francesa, ainda no século XIX.

A lei de 23 de junho de 1857 considerava como marca de fábrica e de comércio, os nomes sob uma forma distintiva, as denominações, os emblemas, os timbres, os relevos, sujeitando-se tal disposição às restrições previstas em outros diplomas legais. Assim, por conta de leis repressoras ao ultraje e aos bons costumes, como as Leis de 2.8.1882, de 16.3.1898 e de 7.4.1908, passou a se considerar como delitos a venda, a colocação à venda, o oferecimento ao público, à exposição e a distribuição em via pública e em lugares públicos, de desenhos, gravuras, pinturas, emblemas, objetos e imagens obscenos ou contrários aos bons costumes. (SOARES, 2003, p. 195).

Foi por intermédio da Convenção da União de Paris (CUP) de 20.3.1883 que a lei internacional contemplou, pela primeira vez, dispositivo contrário ao registro de marcas contrárias à moral e aos bons costumes. $\mathrm{O}$ artigo 6, quinquies, letra $\mathrm{b}$, com redação conferida pela Revisão de Estocolmo (levada a efeito em 14 de

\footnotetext{
${ }^{3}$ Criado pela Lei 92.597 de 01.07.1992 e publicado no
} Diário Oficial da França de 03.07.1992. julho de 1967), estabelece que só poderá ser recusado ou invalidado o registro das marcas de fábrica ou de comércio mencionadas no presente artigo, nos seguintes casos:

(3) Quando forem contrárias à moral ou à ordem pública e, particularmente, de natureza a enganar $\mathrm{o}$ público. Fica entendido que uma marca não poderá ser considerada contrária à ordem pública pela simples razão de que não está de acordo com qualquer dispositivo da legislação sobre as marcas, salvo no caso em que o próprio dispositivo se relacione com a ordem pública.

Atualmente, o Código de Propriedade Intelectual da França ${ }^{3}$ determina, em seu artigo L. 
711-3 que não podem ser registrados como marca "sinais contrários à ordem pública e aos bons costumes ou cuja utilização é legalmente proibida". Entre os casos mais conhecidos examinados até hoje pela jurisprudência francesa é possível mencionar o da palavra Opium (ópio ${ }^{4}$, considerada lícito para assinalar perfumes, e os das palavras Cannabia e Chanvria ${ }^{5}$, julgadas ilícitas para assinalar, respectivamente, cerveja e bebidas à base de cânhamo (POULLAUDDULIAN, 2011, p. 785). Nota-se, nas decisões francesas, que a associação de substâncias à outra substância que, embora lícita, também pode trazer prejuízos à saúde quando consumida (álcool) ensejou a proibição de utilização dos sinais como marca. Por outro lado, a mesma associação com perfume não foi considerada nociva. Mas quais foram os critérios utilizados na França para tais decisões? É possível concordar com eles, sem hesitações?

LaLONDE e GILSON admitem que problemas de inconsistência e subjetividade são inerentes à legislação marcaria (2011, p. 1533). A

\footnotetext{
${ }^{4}$ Droga extraída de um tipo específico de papoula que pode dar origem a outras drogas como a heroína.
}

análise de marcas, segundo os autores, "envolve mais arte do que ciência”. E acrescentam:

$$
\text { Com }
$$
marcas

$$
\text { potencialmente }
$$

escandalosas ou imorais, os conceitos de moralidade e a necessidade de considerar a ofensa pessoal acrescentam outros patamares de dificuldade. Enquanto outros aspectos da lei marcária também estão fundamentalmente preocupados com a psicologia humana, esses casos adicionam elementos desconfortáveis e a necessidade de discernir normas sociais [...] (Ibid, p. 1533$){ }^{6}$

\footnotetext{
5 Alusivas, respectivamente, à cannabis e ao cânhamo, plantas das quais se pode extrair a maconha.

6 Tradução livre.
} 
institucional clara e coesa por detrás das decisões

A maior dificuldade encontrada pelo escritório norte-americano de propriedade intelectual, o USPTO (United States Patents and Trademark Office $)^{7}$, na aplicação de disposições legais que visam coibir o registro de marcas imorais, é geralmente a mesma encontrada na maior parte das entidades congêneres dos demais países: a falta de padrões técnicos independentes a serem aplicados por um amplo rol de examinadores - indivíduos com as mais variadas formações políticas, religiosas, geográficas e familiares. Outro problema relevante diz respeito a como definir se há ou não uma visão do público em geral acerca do potencial ofensivo de uma marca. É possível, tanto para o USPTO, quanto para qualquer outro escritório nacional de propriedade intelectual (como o INPI), apreender aquela visão a partir dos seus procedimentos de exame? Enfim, existe uma moralidade

\footnotetext{
7 Agência federal responsável por garantir o registro de patentes e marcas nos Estados Unidos. Para mais informações ver www.uspto.gov.

${ }^{8}$ Mencione-se, no âmbito judicial, o caráter precursor da decisão do Federal Circuit, de 1938, alusiva ao pedido de registro feito por Riverbank Canning Co para a marca Madonna, que visava distinguir vinhos. A Corte Judicial concluiu que a marca incorria na proibição, em face do produto em questão, uma bebida alcoólica. Como
}

do USPTO? (ibid, 1477).

Em razão dessas dificuldades, LaLONDE e GILSON propõem avançar na seara técnica de avaliação de procedimentos. Para tanto, se valem de uma ampla e rigorosa retrospectiva da jurisprudência norte-americana em relação às marcas imorais. Para efeito deste artigo, interessam particularmente as decisões mais recentes da jurisprudência $\operatorname{administrativa~}^{8}$, ou seja, as afetas ao USPTO, por meio de seus examinadores de primeira instância (examining attorneys) e do seu órgão revisional, o Trademark Trial and Appeal Board (TTAB). A previsão legal que proíbe o registro de marcas imorais nos Estados Unidos se encontra no Lanham Act, aprovado no Congresso em $1946 .{ }^{9}$ Mais especificamente, dispõe o $§ 1052$ (a) que deverá ser negado o registro a toda marca que "consiste em ou compreende matéria imoral, enganosa ou

oportunamente frisa SOARES (ibid, p. 197), é se de registrar que a decisão considerou que Madonna no caso se reportava à Nossa Senhora e não à famosa cantora, nem mesmo nascida na época.

9 Trata-se do diploma que determinou a criação de um sistema federal de registro para proteger as marcas utilizadas no comércio. A proibição já aparecia antes no Federal Trademark Statute, de 1905, que foi incorporado pelo Lanham Act. (GUGGENHEIM, 1999, p. 292). 
escandalosa" ${ }^{10}$. Na ausência de definiçõos mais

precisas sobre os termos "imoral" e

“escandalosa"11, eles podem ser entendidos como

"causando ou tendendo a causar escândalo;

chocando o sentido da verdade, a decência ou a

propriedade; desonroso, ofensivo, infame,

vergonhoso ou, ainda, ofendendo a consciência

ou os sentimentos morais, excitando a reprovação

etc" (SOARES, op. cit, p. 197).

Um dos casos mais ilustrativos que refletem os impasses e dificuldades enfrentados pelo USPTO na aferição de marcas consideradas imorais ou escandalosas é o que se refere à utilização do acrônimo $M I L F .^{12}$ Entre 2000 e 2010, vinte pedidos de registros de marca com a expressão foram recusados pelos USPTO, ao passo que outros 20 foram aceitos LaLONDE e GILSON, op. cit, p. 1481). Os pedidos de registros abrangeram os mais diferentes produtos e serviços, sendo difícil extrair um critério uniforme que tenha ditado tais decisões. Entre as

10 Texto original: Consists of or comprises immoral, deceptive, or scandalous matter.

11 Quanto à marca deceptiva ou enganosa, é aquela que "induz falsa indicação acerca da origem, natureza, qualidade ou utilidade do produto ou serviço assinalado. [...] Faz-se valer o princípio da veracidade das marcas [...]" (DE OLIVEIRA, 2004, p. 26). A inclusão do termo marcas registradas se encontram Milf Magnet, Milf Date e Milf Next Door, ao passo que foram recusados os pedidos para Want Milf? e Got Milf? (para roupas) e Milf $X X X$ (para um site de entretenimento de adultos).

Caso interessante envolveu o pedido de registro para a marca Milf Cosmetics Moms Intent on Loooking Fabulous, com vistas a distinguir produtos de cosméticos:

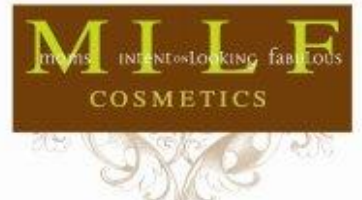

Figura 01: Milf Cosmetics Fonte: Site do USPTO (2015).

Sublinhe-se que fundamental para o registro do sinal foi o fato do acrônimo estar associado à outra ideia, sem conotação vulgar ou chula: a de mães que buscam ficar fabulosas (bonitas). Fundamental também foi a associação dessa ideia aos produtos assinalados. Não obstante, em cada uma das recusas pelo USPTO

“enganosa" na redação dá margem a algumas interpretações legais, abordadas um pouco mais adiante.

12 Acrônimo nos Estados Unidos para Mom(s) I’d Like To Fuck que, no vernáculo pátrio, em uma tradução polida, pode ser traduzido como "Mães com quem gostaríamos de transar". 
de pedidos de registros de marcas com o acrônimo (sem alusão a qualquer outro possível sentido do mesmo), foi de fato a presença em si do termo que foi considerada vulgar, ofensiva e escandalosa, independentemente dos produtos ou serviços envolvidos. Nota-se, claramente, um impasse em relação ao critério técnico recomendável de exame para acolher ou não a tese de que determinado termo constitui ou não ameaça à moralidade, já que o mesmo número de pedidos de registros, com o mesmo acrônimo, foi aceito.

O fato é que a proibição às chamadas marcas imorais ou escandalosas nos Estados Unidos, a exemplo do que ocorre em outros sistemas legais, não se encaixa naquele que costuma ser o objetivo fundamental das legislações sobre marcas que é o de proteger os consumidores de práticas enganosas ao consumidor e de práticas desleais de comércio (LaLONDE e GILSON, op. cit, p. 1487). Pelo contrário, ainda que marcas possam ser consideradas imorais ou escandalosas, elas não necessariamente serão enganosas ou deceptivas. Significa dizer que podem identificar perfeitamente a origem de seus produtos e serviços e serem distintivas no mercado, ou seja, impassíveis de serem confundidas ou associadas com as marcas de seus competidores. Além disso, em termos de elementos de prova, ao contrário do que ocorre com as marcas deceptivas ou enganosas, em que um examinador de marcas pode exigir apresentação de elementos probatórios capazes de afastar a incidência da proibição legal, no caso das marcas imorais ou escandalosas este mesmo examinador muitas vezes só pode confiar no seu bom senso, ancorado em pesquisas realizadas em dicionários e, hoje em dia, em artigos, blogs e outras fontes encontrados na rede mundial de computadores (ibid, p. 1488). Portanto, avançar no estabelecimento de critérios técnicos de exame é fundamental de modo a diminuir a margem de subjetividade na definição do que consiste uma marca imoral ou escandalosa. LaLONDE e GILSON prestam uma contribuição importante nesse sentido ao listar alguns parâmetros do USPTO em seus exames e as principais categorias ou referências temáticas em que pedidos de registros de marcas costumam 
ser negados com base no dispositivo legal que obstaculiza as marcas imorais.

Um dos critérios utilizados pelo USPTO consiste em examinar o pedido de registro de marca tendo em conta o contexto dos produtos ou serviços que se visa assinalar, enfim, o segmento de mercado envolvido (ibid, p. 1490). No já mencionado e precursor caso Madonna, de 1938, a recusa se deu não porque o termo foi considerado imoral e escandaloso em si, mas sim em função da conexão estabelecida entre $o$ mesmo com vinhos. Por outro lado, em 1972, o Board do USPTO considerou registrável a marca Acapulco Gold (uma gíria para "maconha") para loção de bronzear por entender que a expressão remeteria muito mais ao famoso balneário mexicano do que à droga ilegal (ibid, p. 1491). O fato do Lanham Act se referir, na redação do $\S$ 1052 (a), também à expressão “deceptivas”, colocada entre "imorais" e "escandalosas", reforça algumas interpretações no sentido de que o caráter imoral ou escandaloso não pode desconsiderar os produtos e serviços envolvidos, em cada caso examinado.
Não obstante, ao longo de sua história, o USPTO negou o registro como marca de alguns termos ou expressões considerados imorais e escandalosos per se, independente dos produtos e serviços a distinguir, em uma demonstração evidente de que não há um consenso institucional acerca da necessidade ou não de se considerar o segmento de mercado envolvido. A guisa de exemplificação, o Board do escritório norteamericano de propriedade intelectual considerou a expressão Bull Shit, de conotação chula nos Estados Unidos, impassível de registro para qualquer produto ou serviço (Ibid, p. 1491).

Outro procedimento defendido pelo USPTO em algumas de suas decisões é o de considerar qual a composição substancial do público em geral que pode ser mais diretamente afetada pelo registro de uma marca imoral ou escandalosa. De acordo com esse critério, se espera que o USPTO não decida se valendo unicamente de suas visões e valores, mas buscando obter informações sobre as visões da parcela da população potencialmente atingível pela comercialização de determinado produto ou prestação de determinado serviço (ibid, 1493). 
Mesmo assim, o Board negou os registros das marcas Cumfiesta e Cumgirls ${ }^{13}$ para assinalar serviços de entretenimento on line para adultos, levando em conta mais o público em geral do que os consumidores em potencial, a saber, os maiores de idade, usuários de conteúdo erótico na internet que, muito provavelmente, não se sentiriam chocados com aquelas marcas (ibid, p. 1494). Por outro lado, a mesma instância decisória do USPTO afirmou, em outro julgado, não ter encontrado evidência suficiente para considerar a expressão Cumbrella ${ }^{14}$ imoral ou escandalosa para ser aposta em preservativos masculinos (Ibid, p. 1516).

Mais um aspecto que, por vezes, é considerado pelo USPTO para efeito de aferir se um sinal reivindicado para registro como marca deve ou não ser considerado imoral ou escandaloso é o da intenção do depositante do pedido ou futuro titular em potencial. Em geral, a intenção do depositante pouco importa para efeito do exame técnico a ser realizado. Mas em algumas situações, o Board levou em

13 "Cum" é uma palavra em inglês que pode ser traduzida como "gozo" ou "ejaculação". consideração o que definiu como "boas intenções" do requerente do pedido e sua comprovada disposição de não promover embaraço ou ofensa. Foi o que aconteceu no caso da marca Old Glory Condom Corp: O requerente vendia preservativos em pacotes em que se podia vislumbrar uma bandeira dos Estados Unidos em formato de uma camisinha, acompanhada abaixo pela expressão Old Glory Condom Corp:

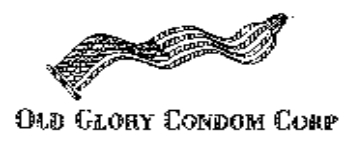

Figura 02: Old Glory Condom Corp Fonte: Site do USPTO (2015).

O requerente do pedido de registro da marca, buscando reverter decisão contrária por parte de um dos examining attorneys do USPTO, enfatizou em sua apelação ao Board sua disposição não de ofender o macular o sentimento de patriotismo, mas sim de redefini-lo incutindo no mesmo a luta contra as doenças sexualmente transmissíveis, especialmente a AIDS. A tese foi acolhida. Contou para a reforma da decisão pela

\footnotetext{
14 Aglutinação das palavras "Cum" e "Umbrella" ("guardachuva).
} 
instância revisora o fato do presidente da empresa requerente do pedido de registro ter participado, antes de começar a comercializar os preservativos, de uma exibição no prestigiado Massachusetts Institute of Technology (MIT) focada em "respostas artísticas" a problemas sociais e políticos contemporâneos. Na ocasião, sua participação se deu por meio da utilização de símbolos nacionais como forma de enfatizar que a luta contra a AIDS e outras doenças sexualmente transmissíveis deveria passar a constituir um dever patriótico (ibid, p. 1523).

A moralidade institucional do USPTO se manifestou até os dias atuais em uma série de decisões sobre marcas imorais e escandalosas em torno das mais diferentes referências temáticas, destacando-se aquelas relacionadas às religiões e etnias, ao sexo e às drogas. No que se refere às questões religiosas e étnicas, em decisão de 2010, o Board recusou o registro da marca Lebanese Arak ${ }^{15}$ (Arak libanês). A alegação foi a de que o critério para a negativa de marcas que podem ofender membros de algum

${ }^{15}$ O Arak é uma bebida alcoólica destilada da família do anis. grupo religioso ou étnico deve repousar na que elas sejam consideradas depreciativas por aqueles. Ou seja, a preocupação, nessas situações, deve estar colocada sobre aqueles que compartilham determinados dogmas e crenças (ibid, p. 1511). Casos anteriores já haviam seguido o mesmo entendimento. ${ }^{16}$

Decisão paradigmática em relação a questões étnicas, que suscitou bastante interesse midiático e acadêmico, foi a que se deu em 02 de abril de 1999, ocasião em que o Board decidiu pelo cancelamento de sete marcas dos Redskins, o time profissional de Washington D.C da National Football League (NFL) - a liga de futebol americano. A Harjo, uma entidade representativa de comunidades nativas dos Estados Unidos, ingressou em 1994 com uma petição no USPTO requisitando o cancelamento de todas as marcas Redskins, inclusive as utilizadas nos capacetes dos jogadores e em seus uniformes. A alegação foi a de que a expressão Redskins - "peles-vermelhas" - seria pejorariva, depreciativa, degradante, ofensiva, infame,

\footnotetext{
${ }^{16}$ Em 1959, o Board recusou o registro da marca Senussi para cigarros por se tratar do nome de uma seita islâmica que proíbe o fumo.
} 
desdenhosa, desonrosa e racista em relação aos índios norte-americanos (GUGGENHEIM, op. cit, p. 293). A Pro Football Inc, detentora das marcas Redskins, apresentou defesa, sustentando, entre outros pontos, ameaça à liberdade de expressão (infringência da Primeira Emenda da constituição), falta de legitimidade para agir da Harjo e ausência de danos em relação à peticionária, uma vez que não seria razoável entender que as marcas requisitadas pudessem estar se referindo aos índios, mas sim, exclusivamente, ao time de futebol. As marcas Redskins, além de não serem depreciativas, teriam adquirido significado próprio pelo uso $^{17}$, sendo plenamente dissociáveis dos nativos americanos (Ibid, p. 293-295).

Sobre as questões constitucionais levantadas pela Pro Football Inc, o TTAB decidiu que fugiam ao escopo de sua competência e que deveriam ser submetidas ao crivo do judiciário. O Board rejeitou ainda o argumento de que a Harjo não teria legitimidade para agir, por

17 Trata-se do chamado "princípio da distintividade adquirida" (secondary meaning).

${ }^{18} \mathrm{O}$ judiciário confirmou, há pouco, a decisão do USPTO. A decisão, contudo, ainda está sujeita à apelação à Suprema ela ter demonstrado sua crença de que a expressão seria depreciativa quando aplicada aos nativos americanos. Definiu, ainda, que para determinar se as marcas eram ou não depreciativas, o critério a adotar não é a opinião do público em geral, mas somente as percepções daqueles que se sentem identificados ou referidos pelas marcas em discussão. (Ibid, p. 294-196).

A decisão do TTAB de cancelar os registros das marcas Redskins se deu exclusivamente com base no fato de terem sido consideradas depreciativas para os nativos norteamericanos. Não obstante, o Board fez questão de frisar que o uso das marcas no mercado não estaria proibido, apenas as marcas não poderiam gozar mais dos benefícios propiciados pelo registro. No entanto, a instância revisora do USPTO rejeitou as alegações da Harjo de que as marcas seriam escandalosas, já que não se teria comprovado que elas ofendem a consciência ou os sentimentos morais de uma composição substancial do público em geral (ibid, p. 301). ${ }^{18}$

Corte dos Estados Unidos. Ver notícias no portal do periódico TIMES (2015). Disponível em: <http://time.com/3949330/washington-redskinstrademark-cancelation/>. Acesso em 17 de julho de 2015. 
No que concerne às referências sexuais, o

USPTO tem rejeitado as marcas que entende conter gírias de baixo calão. Foi o que ocorreu com o pedido de registro da marca Pussy para distinguir bebidas, entre elas as energéticas. $\mathrm{O}$ Board afirmou que o termo possui um significado sexual ofensivo e vulgar e que seria esse mesmo significado o que uma parcela relevante do público em geral perceberia associada aos produtos Em contraponto, foram permitidos, respectivamente em 1952 e 1973, os registros de marcas como Libido para perfumes e Weekend Sex para revistas (LaLONDE e GILSON, op. cit, p. 1514-1515).

Quanto ao uso de imagens com referências sexuais, USPTO negou o registro da marca Dick Heads, para serviços de bar e restaurante, composta pela figura abaixo:

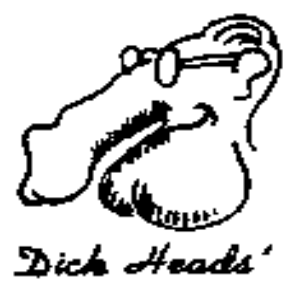

19 "Dick" é também uma das formas populares dos americanos se referirem à genitália masculina.
Figura 03: Dick Heads Fonte: Site do USPTO (2015).

Apesar das reclamações do requerente no sentido de que a expressão era apenas um apelido para Richard Heads `Bar \& Restaurant, o Board decidiu que a impressão que prevalecia no sinal como um todo era a vulgaridade anatômica do desenho, composto pela cabeça de um homem associada à genitália masculina ${ }^{19}$ (Ibid, p. 1517).

Referências a substâncias ilícitas também levaram o USPTO a rejeitar alguns pedidos de registros de marca ou cancelar outros tantos. Objeto de pedidos de vários requerentes, a expressão Cocaine tem sido sistematicamente recusada para produtos como drinques leves e energéticos e cosméticos. O mesmo acontece com a expressão Marijuana. A marca Marijuana Cola, por exemplo, foi negada para drinques medicinais (Ibid, p. 1518-1519). Contudo, marcas que incluem nomes de drogas foram admitidas para registro nos casos em que os produtos e serviços envolvidos não sugerem ou estimulam o 
consumo, ao contrário, visam combatê-lo ou analisá-lo. Foi o que ocorreu com a marca Cocaine Anonymous cujo objetivo estatuído pelo requerente foi $\mathrm{o}$ de promover os interesses daqueles preocupados com o consumo da cocaína e de outros narcóticos, e com a marca Marijuana Symposium, solicitada para conferências no campo da ciência medicinal (Ibid, p. 1519-1520).

Demonstrada a experiência norte-americana com

o que sua doutrina convencionou chamar de "marcas imorais ou escandalosas", passa-se à experiência brasileira.

\section{II - O INPI e as Marcas Imorais: os "sete pecados capitais marcários"}

$\mathrm{Na}$ história legislativa da propriedade industrial no Brasil, o Decreto 16.624, de 1923, reiterando disposições das Leis anteriores (de 1887 e de 1904), proibia o registro de marcas que contivessem palavras, imagens ou representações que envolvessem ofensa individual ou ao decoro público (CERQUEIRA, op. cit, p. 882). Já o Código da Propriedade Industrial de 1945

\footnotetext{
20 Apesar de se reconhecer a necessidade de se exigir análises mais pormenorizadas do dispositivo, recorrermos a uma simplificação: a de considerar que todas as hipóteses
}

(Decreto-Lei no 7903) - em seu artigo 95, item $3^{\circ}$ - ampliava a redação e previa não serem registráveis como marca as expressões, figuras ou desenhos contrários à moral e aos bons costumes e as que envolvessem ofensa individual ou atentassem contra ideias, religiões e sentimentos dignos de consideração. O Código da Propriedade Industrial de 1971 (Lei $\mathrm{n}^{\circ}$ 5.772), em seu artigo 65 , item 3 , vedava o registro como marca de expressão, figura ou desenho contrário à moral e aos bons costumes e os que envolvessem ofensa individual ou atentassem contra culto religioso ou ideia e sentimento digno de respeito e veneração. A atual redação, constante da LPI (artigo 124, inciso III), se assemelha bastante à de 1971 e determina que não são registráveis como marca expressão, figura, desenho ou qualquer outro sinal contrário à moral e aos bons costumes. Igualmente, não é registrável sinal que ofenda a honra ou imagem de pessoas ou atente contra a liberdade de consciência, crença, culto religioso ou ideia e sentimento dignos de respeito e veneração. ${ }^{20}$ Importante mencionar que desde

consagradas na redação legal versam sobre o que aqui se chama de "marcas imorais". 
1843, com a criação do Conservatório Dramático, no âmbito das diversões públicas, já existia uma organização voltada à proteção dos valores morais dos nacionais. Ao longo da história, outras organizações similares foram se sucedendo até serem extintas nos anos 1980 - DOP (1932), DPDC (1934), DIP (1945) etc. ${ }^{21}$

De acordo com item 5.8.2 do Manual de Marcas do INPI, estabelecido pela Resolução INPI/PR no 142/2014, o examinador de marcas deve observar se a expressão, desenho ou figura constantes do sinal são, per se, atentatórias à regra. Assevera que a avaliação técnica feita pelo examinador deve levar em conta as características do segmento de mercado do produto ou serviço que o sinal visa assinalar e o tipo do público-alvo (geral ou específico), bem como os canais de distribuição, comercialização e publicidade dos bens ou serviços em questão. O Manual recomenda ainda, ao examinador, que observe se a palavra, a expressão, o desenho ou a figura são,

\footnotetext{
${ }^{21}$ Para saber mais, ver: MARTINS. W. Produzindo no escuro - políticas para a indústria cinematográfica e o papel da censura (1964-1988). Rio de Janeiro:autografia, 2016.

22 O Manual de Marcas apresenta, ainda, alguns exemplos do que seriam marcas imorais e de sinais que não
}

por si só, atentatórios à moral e aos bons costumes, independente do produto ou serviço ao qual estejam associados ou se adquirem tal conotação somente quando aplicadas a determinados produtos ou serviços. ${ }^{22}$

Antes de se passar ao exame dos casos concretos coletados, vale uma breve explanação sobre a tramitação de um pedido de registro de marca no INPI. ${ }^{23} \mathrm{O}$ sistema jurídico brasileiro é de caráter atributivo. Significa dizer que, em regra, é da publicação da decisão do INPI de concessão do registro na Revista da Propriedade Industrial (RPI) que nasce o direito de propriedade do requerente sobre a marca.

O depósito de um pedido de registro de marca no INPI pode se dar eletronicamente ou por papel, sendo que é pela primeira via que a esmagadora maioria de pedidos é recebida atualmente (mais de $90 \%$ do total). Estando o pedido formalmente correto, ocorre então a publicação na RPI, de modo a ensejar a

incorreriam na proibição legal, mas sem adentrar no mérito de discutir conceitualmente a moral.

${ }^{23}$ Todas as etapas de um pedido de registro de marca estão explicadas no Portal do INPI, em: <http://www.inpi.gov.br/menuservicos/marcas/etapas_processamento_pedido.pdf $>$. Acesso em 21082015. 
manifestação de possíveis interessados que desejem apresentar oposição com razões contrárias ao possível deferimento do pedido. A oposição deve ser protocolizada em até 60 (sessenta) dias contados da data da publicação do pedido (artigo 158 da LPI). Após, será publicada na RPI a oposição para que o requerente se manifeste também no prazo de 60 (sessenta) dias. A manifestação não é compulsória.

De acordo com o artigo 159, decorrido o prazo de oposição ou, se interposta esta, findo o prazo de manifestação, será feito o exame, durante o qual poderão ser formuladas exigências, que deverão ser respondidas no prazo de 60 (sessenta) dias. ${ }^{24}$ Concluído o exame, será proferida decisão, deferindo ou inferindo o pedido do registro (artigo 160). O órgão responsável pelos exames e pelas decisões acerca dos pedidos de registros de marcas depositados é a Diretoria de Marcas (DIRMA), na forma estabelecida pelo artigo 18, inciso I, do Decreto $\mathrm{n}^{\circ} 7.356$, de 12 de novembro de 2010 (que definiu

${ }^{24} \mathrm{O} \S 1^{\circ}$ do artigo 159 determina que, não respondida a exigência, o pedido será definitivamente arquivado.

$25 \mathrm{O}$ processo administrativo de nulidade pode ser instaurado de ofício ou mediante requerimento de qualquer a atual estrutura regimental do INPI). A decisão tomada pela DIRMA poderá resultar no deferimento ou no indeferimento do pedido (artigo 161 da LPI).

Portanto, as decisões de mérito do INPI envolvendo os pedidos de registros de marcas podem ter dois deslindes: o indeferimento (recusa) com base em algum impedimento legal ou o deferimento (aceite), com a posterior concessão, depois de cumpridas algumas exigências relacionadas ao pagamento de taxas para a proteção da marca, cujo prazo é decenal (contado da expedição do certificado de registro), prorrogável por períodos iguais e sucessivos. Toda decisão de indeferimento poderá ser alvo de recurso (artigo 212 da LPI), ao passo que todo registro deferido e posteriormente concedido está sujeito, ainda, a processo administrativo que vise obter a declaração de nulidade do registro (artigo 168 da LPI). ${ }^{25}$

Por lei, cumpre ao Presidente do INPI decidir os recursos e processos administrativos de

pessoa com legítimo interesse, no prazo de 180 (cento e oitenta dias) contados da data da expedição do certificado de registro (artigo 168, da LPI). 
nulidade, encerrando a instância administrativa. ${ }^{26}$

Diante da necessidade da de um órgão que concentrasse todas as decisões do Presidente, em grau de segunda (e última) instância, o Decreto ${ }^{\circ}$ 7.356/10 criou a Coordenação-Geral de Recursos e Processos Administrativos de Nulidade (CGREC), responsável, entre outras atribuições, por: examinar e fornecer subsídios técnicos para decisão do Presidente do INPI nos recursos e processos administrativos de nulidade, interpostos na forma da legislação vigente de propriedade industrial, emitindo parecer sobre a matéria técnica suscitada; examinar e fornecer subsídios técnicos para decisão do Presidente do INPI nos demais recursos em matéria de propriedade intelectual, cuja competência do registro seja atribuída ao INPI por força de lei

\footnotetext{
${ }^{26}$ Encerrada a instância administrativa, a única forma de questionar e tentar reverter um ato do INPI é a via judicial, sendo a Justiça federal a competente para o ajuizamento da ação respectiva.

${ }^{27}$ Em regimentos anteriores, a CGREC foi precedida por instâncias recursais com outras denominações e algumas formas diferentes de composição e de operacionalização. Por isso, quando as decisões mencionadas no trabalho forem ancoradas em pareceres da lavra de antecessoras regimentais da CGREC, serão utilizadas expressões como "segunda instância", "instância recursal” ou "instância revisora".
}

(artigo 21, incisos I e II, do Decreto $\mathrm{n}^{\mathrm{o}} 7.356 / 10$ ). 27

\section{Como a Diretoria de Marcas e a CGREC}

vêm decidindo acerca de pedidos de registros de marcas indeferidos com base no inciso III do artigo 124, da LPI? Quais temas têm suscitado mais indeferimentos? Quantas decisões foram reformadas e mantidas $?^{28}$ Por quais fundamentos? É possível identificar um padrão técnico harmonioso de exame entre as duas instâncias administrativas do INPI?

Metodologicamente, se agrupou as incidências mais recorrentes nos dados coletados por afinidade temática. Buscou-se então identificar os padrões morais que orientaram as decisões dos examinadores de marcas. As sete categorias resultantes, que denominamos de "sete pecados capitais marcários" foram as seguintes:

\footnotetext{
28 Por dificuldades técnicas na obtenção dos dados, trabalhou-se, apenas, com decisões da segunda instância em recursos contra decisões de indeferimento. Não tivemos acesso a eventuais decisões em processos administrativos de nulidade. Não obstante, não é exagero dizer que, se existirem tais casos, deverão ser de bem pequena monta. Processos administrativos de nulidade (à exceção do que é movido de ofício, pelo próprio INPI) necessitam de um interessado em obter a nulidade de um registro de outra pessoa, o que na prática administrativa do INPI é bastante comum em outras hipóteses legais como, por exemplo, as dos incisos V, VI e XIX, do artigo 124, da LPI, mas não a do inciso III.
} 
substâncias ilícitas, nudez, obscenidades, religiosas, desviantes, ideológicas e sinais polissêmicos. Abaixo, se discute as características de cada uma dessas categorias, a partir de exemplos de sinais indeferidos em pedidos de registros de marcas:

\section{1) Substâncias ilícitas: o} indeferimento na DIRMA costuma ocorrer independente do produto ou serviço a que se refira o sinal. Basta que a marca seja constituída por apelido de substância entorpecente (hemp ou maconha), gíria (“baseado”), nome científico (cannabis sativa), desenho ou imagem de planta, erva, comprimido, líquido ou pó percebido pelos examinadores como sendo substância de uso proibido. No limite, é só o examinador entender que o 'contexto' da imagem remete ao uso de substância entorpecente - como no caso do sinal Reggae In Bahia $^{29}$, abaixo reproduzida - para que a marca seja considerada ofensiva à moral e aos bons costumes. Na figura 4, agrupamos alguns exemplos que expressam esse entendimento:

\footnotetext{
${ }^{29}$ No despacho que indeferiu o sinal, o examinador justifica que a figura apresenta: "forte indício de referência a substância entorpecente proibida."
}
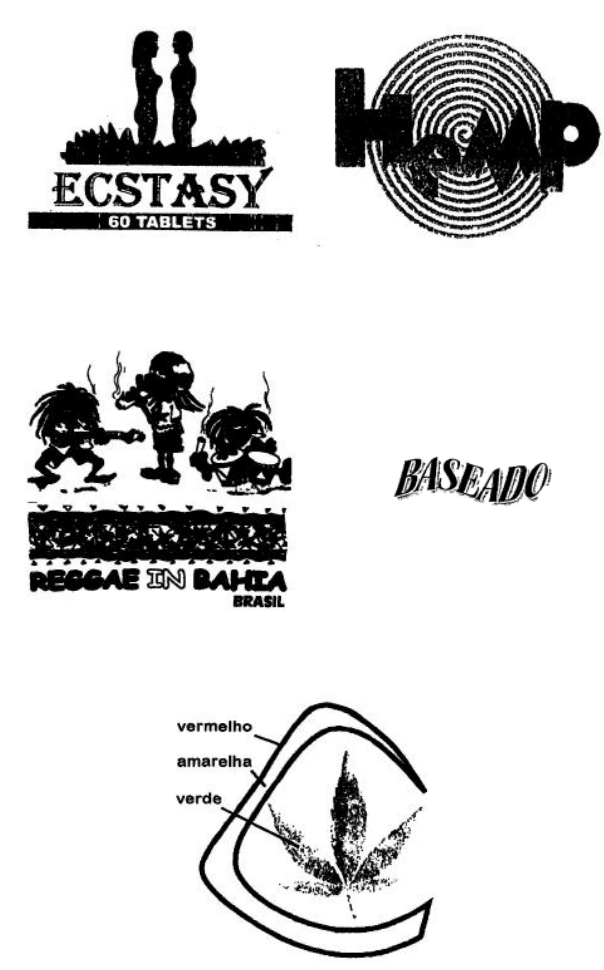

Figura 4: Marcas indeferidas na categoria Substâncias Proibidas. Fonte: SINPI/INPI (2015)

Os sinais supracitados foram requeridos, respectivamente, para proteger os seguintes produtos ou serviços: medicamentos; calçados e vestuário; vestuário; bebidas alcoólicas e fios e materiais têxteis.

No tocante à segunda instância, diferentes decisões foram dadas envolvendo a palavra Hemp. Em três pedidos de registro para os sinais 
Planet Hemp, destinados a assinalar serviços como comerciais de rádio e televisão e de espetáculos ao vivo ou produtos como jornais e revistas, houve reforma das decisões de indeferimento. Apesar de não se ter tido acesso aos pareceres técnicos que orientaram tais decisões, se pode cogitar que a característica de maior liberalidade de comportamento do segmento de entretenimento concorreu para a mudança do entendimento institucional.

2) Nudez - independente do produto ou serviço, assim como na categoria anterior, são tradicionalmente indeferidos os pedidos de registros com sinais que façam menção (com palavras e expressões) ou contenham imagens com os nomes de determinados componentes do corpo humano comumente associadas à sexualidade (seios, lábios vaginais, vagina, pênis, escroto, espermatozoide, nádegas e ânus etc). Não importando o idioma no qual o termo aparece ou se as expressões utilizadas são regionalismos

\footnotetext{
${ }^{30}$ Curiosamente, quando se faz o caminho inverso e se consulta o banco de dados do USPTO se constata que vários são os sinais registrados como marcas contendo as expressões buttock, culo, culitos, bumbum e bunda, dentre
}

comuns, para fins de registro como marca em regra não são aceitos.

Em especial, percebe-se que menções às nádegas são invariavelmente consideradas ofensivas ao padrão de moralidade que deve ser preservado - o que não deixa de ser muito intrigante quando se considera as representações sobre o Brasil que são veiculadas no exterior. Aliás, a palavra buttock (nádegas, bunda em tradução livre), ao ser requerida como marca no INPI para assinalar peças do vestuário, foi indeferida em razão de sua tradução. ${ }^{30} \mathrm{Na}$ figura 5, observamos exemplos de sinais inseridos nesta categoria.

outras - isto é, em uma sociedade cuja matriz moral repousa, em boa parte, na ética protestante, há mais tolerância ao registro dessas expressões do que na "pátria do carnaval". 

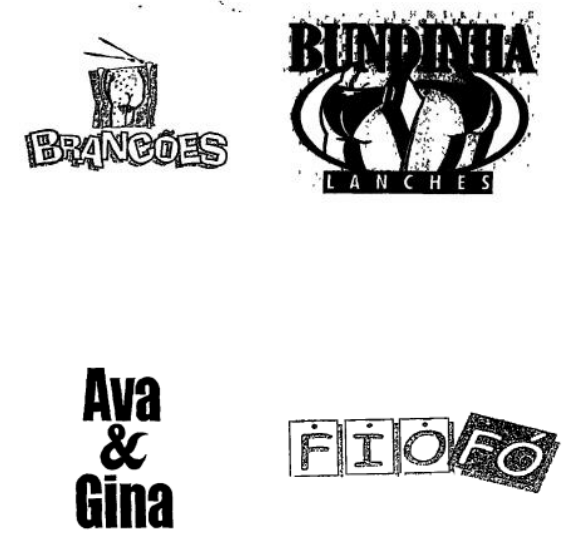

\section{coo's}

Figura 5: Marcas indeferidas na categoria Nudez. Fonte:

SINPI/INPI (2015)

$\mathrm{Na}$ mesma ordem em que as figuras se apresentam, informamos que os seguintes serviços ou produtos foram requeridos por esses sinais: entretenimento; serviços de alimentação; vestuário; revistas e vestuário. No caso específico do sinal Fiofó, foi indeferido o pedido de registro sob a alegação de que "O sinal em tela é dicionarizado, porém como expressão chula, infringindo o dispositivo legal supramencionado". Portanto, não importa se os órgãos sexuais ou as partes íntimas são tratados pelo nome científico, gírias ou regionalismos, para fins do registro como marca no INPI, independente do idioma em que o pedido esteja redigido, essas expressões são entendidas como imoralidades. Caso interessante envolvendo o aspecto da nudez diz respeito ao pedido de registro da marca Catuaba Exótica que foi indeferida pela DIRMA e reformado em grau de recurso para assinalar "bebidas em geral". O sinal requerido foi o seguinte:

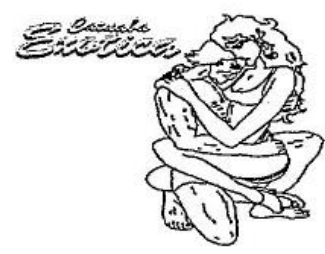

Figura 6: Marca Catuaba Exótica Fonte: SINPI/INPI

A segunda instância reformou a decisão de indeferimento sob a alegação de que o casal retratado na figura não se encontra nu e que sua posição remete a gestos de carícia, mas não de cópula sexual. Outra decisão interessante da segunda instância se refere à reforma do indeferimento do pedido de registro para a marca Dupiru, visando assinalar bebidas e xaropes concentrados. Observa-se que, no segmento de mercado de bebidas (especialmente o de 
aguardentes que, por tradição, recorre a expressões irreverentes e picantes para apô-las aos seus produtos), há maior flexibilidade no sentido de permitir o registro de sinais que poderiam, a princípio, ser considerados atentatórios à moral e os bons costumes.

3) Obscenidades - nesta categoria estão reunidos os sinais constituídos por expressões de baixo calão ou gestos obscenos, de acordo com a DIRMA. Uma curiosidade verificada ao longo da análise é a classificação institucional da palavra "tesão" como termo vulgar ou chulo, portanto, obsceno. Neste caso, resta evidente que os examinadores desconsideram as demais acepções da palavra, inclusive seu uso corriqueiro para expressar intensidade. Agindo assim, concebem performaticamente o ato de descrever ou falar sobre o desejo sexual como obscenidade - o mesmo ocorre com a palavra "orgasmo". Há aí um evidente julgamento de valor que orienta a escolha de uma acepção em detrimento de outras e nos fornece indícios sobre os padrões morais vigentes no Instituto.
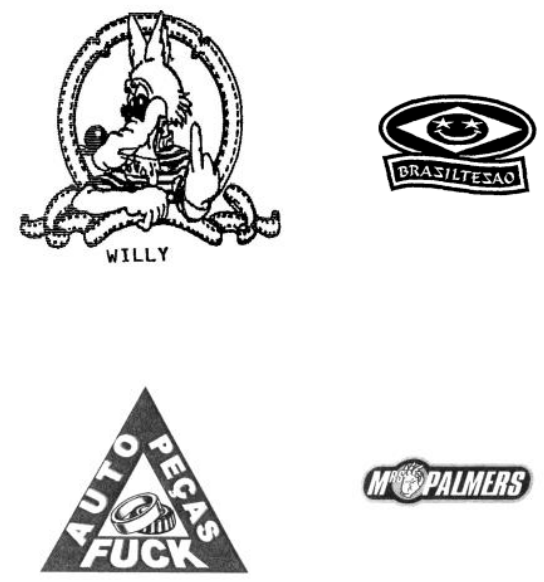

CNATMETS

Figura 7: Marcas indeferidas na categoria Obscenidades Fonte: SINPI/INPI (2015)

No caso dos sinais Willy, Brasiltesão e Mrs. Palmers, a justificativa para indeferimento residiu na imagem contida nos sinais e todos foram requeridos para peças do vestuário. Auto Peças Fuck é autoexplicativo, já o sinal Sacaninha visava assinalar aguardentes. Neste caso, nem mesmo a característica do segmento de mercado de aguardente (que, como dito, habitualmente se vale de expressões irreverentes e picantes), conseguiu convencer os examinadores quanto à possibilidade de registro 
da expressão. A negativa ao registro se sustentou no fato da palavra sacaninha ser derivada de sacana, expressão classificada como chula no dicionário Aurélio. Isto é, observou-se o padrão moral preservado na língua culta para embasar a análise quanto à registrabilidade do sinal. ${ }^{31}$

Em consonância com o entendimento da DIRMA para sinais contendo a palavra Tesão, a CGREC manteve o indeferimento de cinco pedidos de registro para a marca Barretesão uma aglutinação da palavra Barretos (nome de uma cidade do interior paulista muito famosa por seu festival de rodeio) com a palavra "tesão". Destinados a assinalar diversos produtos, os pedidos foram depositados por uma equipe de rodeios. A CGREC negou os pedidos, apesar das alegações da requerente de que já era possuidora de um registro da marca Barretesão para assinalar roupas e acessórios do vestuário e de que os deferimentos dos cinco pedidos constituiriam mera extensão de um direito adquirido. Segundo a instância revisional do INPI, a não aplicação da melhor técnica em uma decisão anterior não

\footnotetext{
${ }^{31}$ Entretanto, a DIRMA concedeu os registros das marcas Rabo Quente e Sá Cana Aguardente de Cana para os mesmos produtos, o que denota que os valores morais de
}

poderia ensejar ampliar o escopo de proteção para além daqueles produtos já protegidos pelo registro erroneamente concedido.

4) Religiosas - Uma especificidade desta categoria reside no fato dela levar em consideração o segmento de mercado no qual o sinal será utilizado. Nas categorias anteriores, as restrições eram universais, não dependentes do produto ou serviço reivindicado. Nos temas religiosos é justamente o contrário: a atenção se volta para o uso comercial da marca. Não é somente o signo em si que está sob análise, mas o seu uso. Neste sentido, o nome de um personagem bíblico ou religioso não encontra previsão de restrição quanto ao seu registro desde que sua associação com o produto não ofenda sentimentos dignos de veneração ou crença. Contudo, há aí um grau de subjetividade que ao ser exposto às afiliações religiosas dos examinadores possibilita entendimentos diversos sobre a questão.

Na figura 8, os sinais Cristo Rei (para graxa), São Vicente (sacos de lixo e papel higiênico) e Notredame Motel (motel) salientam

cada examinador ainda são variáveis intervenientes fundamentais na apreciação da questão moral em pedidos de registros de marcas. 
bem o entendimento ao qual nos referimos. Os sinais Farmácias Irmã Dulce (Farmácias) e Em nome do Santo (bares e restaurantes - reprodução da face de Cristo na figura) embora também tenham apontado os serviços requeridos como justificativa de impedimento ao registro da marca, não conseguem evidenciar de imediato como esses serviços poderiam ser ofensivos aos personagens em questão.
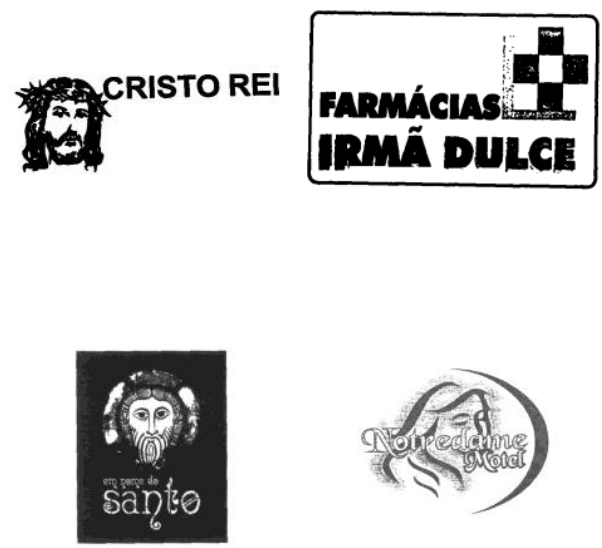

\section{ș̣: visoente}

Figura 8: Marcas indeferidas na categoria Religiosas.

Fonte: SINPI/INPI (2015)

Um exemplo emblemático do grau de liberalidade presente nas decisões dos examinadores da DIRMA pode ser encontrado na decisão denegatória do sinal nominativo Lutero (para vestuário). A justificativa para a decisão sustenta que o sinal remeteria "de maneira inegável” a Martinho Lutero (Martin Luther) um dos articuladores da Reforma Protestante. Desta forma, considerando que o sinal "visa proteger, entre outros produtos do vestuário, uma linha de cuecas e sungas, é do nosso entendimento que tal ligação possa ofender os seguidores das igrejas luteranas". Enfim, trata-se de expressão que é apontada como potencialmente ofensiva às liberdades de crença, mas cuja ofensa tem de ser desvelada pelo examinador para que possa ser conhecida pelos seus pares e pelos consumidores.

Exemplo encontrado de decisão reformada após indeferimento pela DIRMA é o da marca DES Indústria e Comércio de Bebidas Divino Espírito Santo, para bebidas alcoólicas (com exceção de cerveja). Eis o sinal que foi requerido:

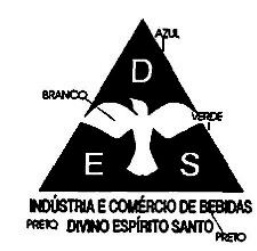

Figura 9: Marca Divino Espírito Santo Fonte: SINPI/INPI (2015) 
Em seu parecer, a segunda instância sustentou que a marca em tela não parecia contrariar sentimentos dignos de respeito e veneração: "a associação de nomes religiosos a bebidas alcoólicas é prática comum. [...] Vários são os exemplos de marcas compostas por nomes de entidades religiosas que assinalam produtos desse gênero". Na mesma linha, em 2002, foi reformada a decisão de indeferimento para a marca Santa Ceia, destinada a assinalar vinhos, vermouts e aguardentes. Neste caso, o sinal requisitado remetia não ao nome de qualquer personagem religioso, mas a uma famosa situação retratada na Bíblia.

5) Desviantes - trata-se da categoria constituída por sinais que tragam em seus nomes ou figuras menções (ou evoquem) às atividades ou produtos relacionados a crimes $\mathrm{e}$ contravenções ou a grupos conhecidos por atuar à margem da lei. A maior parte dos sinais indeferidos pela DIRMA nesta categoria continham apenas palavras ou expressões, sem quaisquer imagens. Eis alguns exemplos: Primeiro Comando da Capital e PCC (vídeos, livros, entretenimento), Máfia Urbana (Roupas),

Comando Vermelho (Roupas), Tendência Criminal (grupo musical) e Base Criminal (grupo musical).

A interdição ao registro do sinal independe do segmento de mercado, basta que ocorra, aos olhos do examinador, algo classificado como "apologia ao crime" ou "remissão a um ilícito penal" para que o impedimento ao registro de caracterize. Na Figura 10 apresentamos alguns exemplos de sinais indeferidos nesta categoria:
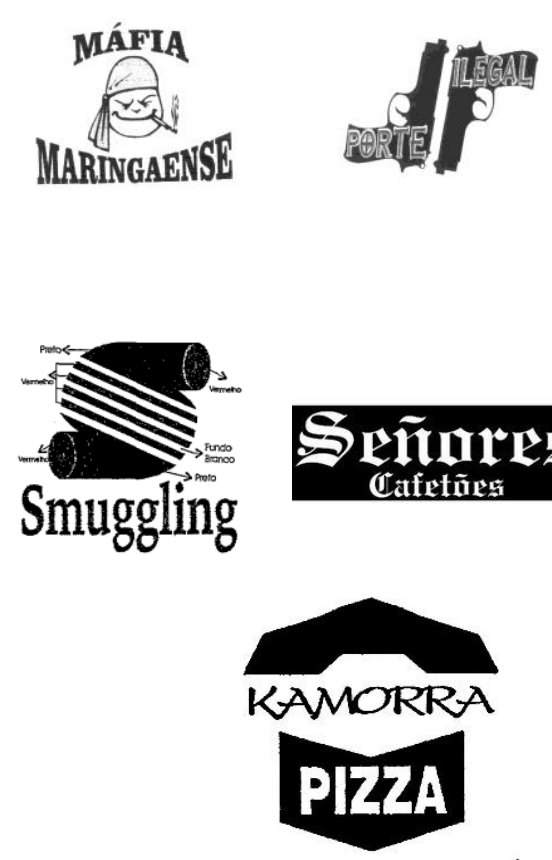

Figura 10: Marcas Indeferidas na categoria desviantes Fonte: SINPI/INPI (2015) 
Os sinais Máfia Maringaense, Porte Ilegal (de armas, como lido pelo examinador) e Smuggling (contrabando) foram requeridos para peças do vestuário. Em Senhores Cafetões (banda musical), há uma ampla explicação sobre a atividade profissional do proxeneta sustentando a decisão quanto à irregistrabilidade do sinal. Já em Kamorra Pizza (serviços de alimentação), presume-se que o grupo mafioso italiano (Camorra) seria suficientemente conhecido do público em geral para se justificar a decisão.

Quanto à segunda instância, vale mencionar o caso do pedido de registro para a marca Clandestina, que visava assinalar bebidas alcoólica e não-alcoólicas. O significado de ilegal ou ilegítimo, a que a palavra se refere, foi fundamental para a manutenção do indeferimento.

6) Ideológicas - neste grupo se encontram os signos que são indeferidos por critérios político-ideológicos. Deve-se ressaltar que, embora a Lei de Propriedade Industrial tenha no território nacional o limite de sua aplicabilidade, os valores que se encontram ameaçados a partir da possibilidade de registro desses sinais parecem ser extraterritoriais. Neste caso, a ofensa aos costumes se encontra imbricada a defesa de um determinado sistema ou regime de governo, conforme se pode observar na figura 11.

\section{Cento 7 Jeans Wear}
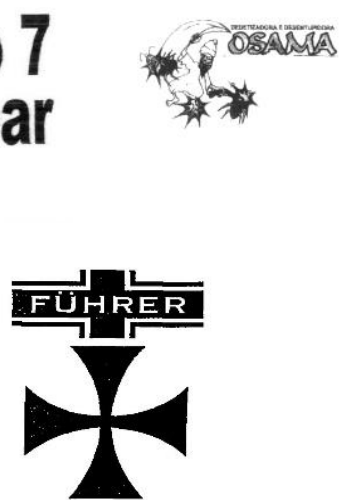

\section{SENDERO LUMINOSO HOLOCAUSTO}

Figura 11: Marcas Indeferidas na categoria Ideológicas Fonte: SINPI/INPI (2015)

No primeiro sinal, requerido para peças do vestuário, o examinador viu uma suástica nazista estilizada, o que impossibilitou o registro. No segundo conjunto, a expressão Osama assinalando serviços de dedetização sugeriria, a seu ver, "ilações de cunho político-religioso". O sinal Führer nem sequer chegou a ser alvo da 
análise dos examinadores, a Procuradoria do Instituto enviara um comunicado interno solicitando o indeferimento do sinal. Sendero Luminoso foi requerido em duas ocasiões distintas, em 1999 (doces) e 2000 (atividades culturais) sendo negado com a seguinte justificativa: "grupo guerrilheiro atuante no Peru". No caso de Holocausto (Banda Musical), o fato a que se refere à expressão exerceu força suficiente para inviabilizar o registro do sinal: “ $O$ termo holocausto ficou conhecido como a execução em massa de judeus elou outras minorias perseguidas, como ciganos, homossexuais...".

Não se observou na segunda instância casos de recursos pedidos de registros envolvendo sinais de caráter político-ideológico.

7) Sinais Polissêmicos - o que caracteriza os sinais reunidos nesta categoria não é o sentido imediato que os mesmos transmitem aos consumidores em uma primeira leitura, mas a particularidade com que os examinadores traduzem esses sinais. Isto é, o impedimento ao registro se encontra na singularidade da leitura.
Para fins de entendimento e clareza quanto aos aspectos a que estamos nos referindo abordaremos cada um dos exemplos apresentados na figura 12.
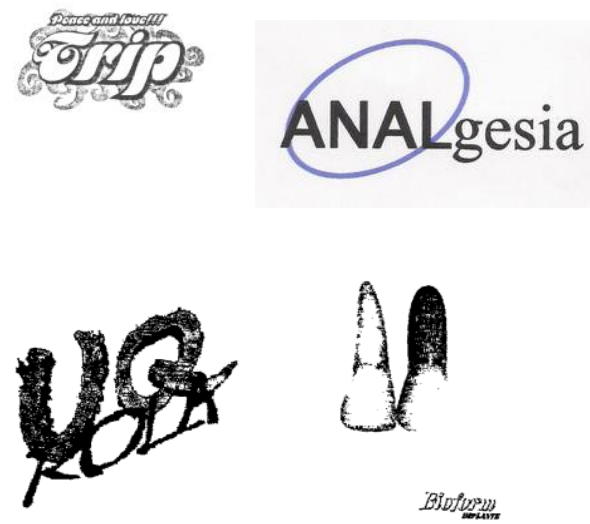

Figura 12: Marcas Indeferidas na categoria Sinais Polissêmicos Fonte: SINPI/INPI (2015)

A negação ao registro do sinal Peace and Love Trip (papel de cigarro) se assenta na seguinte premissa: “ $A$ expressão 'paz e amor'é uma gíria dos hippies e significa 'tranquilo, tudo bem!'. Entre as características associadas aos hippies está o uso de drogas como a maconha, haxixe e alucinógenos como o LSD visando a 'liberação da mente' por sua natureza iconoclasta e ilícita" a justificativa prossegue e, ao encerrar sua tese, o examinador conclui que o sinal é contrário à moral e aos bons costumes. A 
análise do sinal Analgesia (lubrificantes sexuais) apresenta um tom similar: "O termo anal, em destaque na figura, quando associado à finalidade do produto, remete a um tipo de relação sexual (sexo anal) que ainda hoje na sociedade é visto com preconceito, podendo ser percebido como sinal contrário à moral e aos bons costumes". Em ambos os casos, tanto a interpretação dos sinais como a concepção dos valores que devem ser protegidos parecem, no mínimo, controversas. ${ }^{32}$

Já as leituras do sinal $U q$ rola (publicidade; publicação de eventos) e da parte figurativa do signo Bioform Implante (próteses) se situam em outra dimensão polissêmica: naquela em que a questão se encontra no olhar do examinador e não no exame - que desconsidera inclusive os produtos/serviços reivindicados. Afinal, quando se associa expressão $U q$ rola ao serviço de publicação de eventos parece que o sentido pensado para o conjunto marcário foi o de verbo intransitivo (o que acontece) e não o de

\footnotetext{
${ }^{32} \mathrm{O}$ preconceito parece uma chave explicativa instigante para se pensar o julgamento moral em pesquisas futuras, tendo em vista que se caracteriza por ser uma valoração
}

substantivo feminino (Uh, que pênis) como restou entendido pelo examinador. Análise similar se verifica na decisão do sinal Bioform Implante no qual a reprodução figurativa de uma prótese dentária é interpretada como uma figura que atenta contra a moral e os bons costumes. Nos dois casos, a suposta imoralidade ou ofensa à sociedade se alimenta de uma atitude de suspeição preventiva que, por vezes, ingressa na atividade de exame.

Caso interessante sobre sinal polissêmico, mais recente, e que talvez aponte uma nova tendência de exame no INPI, se encontra nas decisões da DIRMA de deferimento de dois pedidos de registros para as marcas Power Guido, uma delas para bebidas energéticas nãoalcoólicas (e produtos similares) e outra para bebidas alcoólicas e essências alcoólicas para colocar em bebidas etc. Considerou a DIRMA os sinais registráveis não obstante a ideia que expressão pode adquirir quando lida, pela sua fonética, que remete à ereção masculina.

negativa de algo que se desconhece e que é disseminado através das gerações. 
Entre os dados coletados, a segunda instância não interviu em qualquer caso relacionado a essa categoria.

\section{Considerações}

Considerando a natureza exploratória do presente estudo, se apresenta algumas considerações gerais sobre os dados analisados. Observa-se que uma ligeira inclinação ao conservadorismo nas práticas institucionais tem sido uma característica permanentemente verificada nas decisões administrativas dos examinadores do INPI em processos de registros de marcas, salvo poucos casos em que uma posição um pouco mais liberal prevaleceu. Notase que os critérios que sustentaram essas decisões de indeferimento pouco se modificaram ao longo dos últimos anos, contexto no qual transformações políticas, econômicas, culturais, sociais e tecnológicas impactaram bastante nossa sociedade tanto no acesso como na divulgação de informações e conteúdos diversos. Atualmente, por exemplo, não apenas a imagem de um preservativo como o modo correto de usá-lo é algo corrente nas campanhas promovidas pelo Ministério da Saúde, mas passível de indeferimento se constituir parte de signo requerido como marca. Por outro lado, a renovação substancial pela qual passou o corpo de servidores que atuam no exame de marcas do INPI nos últimos 15 a 20 anos, por força, entre outras causas, de concursos públicos realizados, não parece ter sido estímulo suficiente para renovar e adensar diretrizes de análise e modificar substancialmente entendimentos cristalizados sobre a questão da moralidade e sua relação com as marcas. Mas se a censura moral era uma forma de interlocução entre a sociedade civil e o Estado durante o regime militar (Martins, 2016), com a redemocratização isso não deveria ter se alterado?

De um modo geral, os dicionários têm sido a fonte de consulta principal que tem orientado às decisões quanto à registrabilidade dos sinais. Embora essa tenha se mostrado uma estratégia funcional, são evidentes as perdas e o empobrecimento que a medida acarreta: ironias, deboches, escárnios, trocadilhos e metáforas são, por vezes, reduzidos aos sentidos dicionarizados das expressões, comprometendo atitudes que 
foram pensadas na elaboração de determinados

signos. Isso é bem evidente nos sinais

reivindicados para atividades culturais que foram negados, como os blocos carnavalescos (Só vai quem Chupa, Suvaco de Cristo etc), os programas televisivos e humorísticos teatrais ( $O$ Grelo Falante, A Bicha como ela é, Sexo Oral etc) e os grupos musicais (Ardência no Regasso, Psirico, Buli com Tu etc).

Em algumas situações, a interpretação do examinador se assenta em valores que parecem mais derivados de preconceitos sociais - bastante comuns a todos nós, mas que podem e devem ser objeto de reflexão e crítica - do que em efetivas ofensas à moral, aos bons costumes, às liberdades ou aos sentimentos dignos de veneração e respeito. Não se está com isso afirmando que essas decisões estejam tecnicamente incorretas, não é esse o objetivo! Interessa apenas destacar a necessidade de se evidenciar mais, durante o exame, eventuais características sociais e culturais do segmento de mercado envolvido, assim como os produtos e os serviços para os

\footnotetext{
${ }^{33}$ Ficou bastante conhecido, na mídia, o caso da propaganda da cerveja Devassa, com a socialite internacional Paris Hilton, por ter sido considerada ofensiva às mulheres.
}

quais o sinal foi requerido, para fins de aplicação do inciso III do art. 124 da LPI. Decisões interessantes podem ser observadas, por exemplo, em pedidos de registros no mercado de bebidas, especialmente no segmento de bebidas alcoólicas, como as aguardentes.

A experiência norte-americana com as marcas imorais demonstra uma realidade de bastante engajamento de entidades e movimentos da sociedade civil na vigilância de pedidos de registros de marcas potencialmente ofensivos a determinados grupos étnicos ou às ditas minorias de forma geral. O caso Redskins é o exemplo mais ilustrativo dessa tendência à mobilização. No Brasil, movimentos semelhantes são bem escassos em assuntos envolvendo marcas. Mobilização ainda incipiente, mas semelhante à encontrada nos Estados Unidos, se apresenta mais no campo publicitário e na defesa do consumidor, em algumas decisões de retirada do ar de propagandas, tomadas pelo Conselho de Autorregulamentação Publicitária (CONAR). ${ }^{33}$ 
Nos Estados Unidos, se nota ainda uma disposição permanente, por intermédio de exaustivas argumentações, em demonstrar que o potencial ofensivo do sinal não atinge apenas as concepções de vida e visões de mundo do examinador, mas ao público em geral. No caso brasileiro, isso é menos evidente, bastando que a ofensa seja percebida como tal pelo responsável pelo exame para que o sinal seja indeferido. Daí se abrir mais espaço, por vezes, para decisões que podem soar destoantes ${ }^{34}$, não que estas também não se observem no USPTO.

Por fim, como sugestões para pesquisas futuras, um mergulho mais detalhado e profundo no rol de casos coletados, e de outros mais recentes, se faz necessário. Pretende-se que este trabalho seja recepcionado como uma primeira grande aproximação no exame específico do tema. Metodologicamente, procurar conhecer melhor, no futuro, o perfil político-ideológico, social, cultural e religioso do corpo de examinadores do INPI pode se revelar uma

\footnotetext{
${ }^{34}$ Mencione-se a decisão de indeferimento do pedido de registro da marca Aguardente de Cana Maltada Du Piru, para assinalar bebidas em geral, em contraste com a recente concessão do registro da marca Hot Dog Du Piru para
}

estratégia interessante para conferir maior compreensão, do ponto de vista externo, às decisões do Instituto. Entende-se que isso vale não somente para o Brasil. Mesmo nos Estados Unidos, parece não haver quem tenha avançado com estudos nesse sentido.

Eliminar por completo a subjetividade no exame de marcas consideradas imorais parece uma tarefa impossível. No entanto, se pode avançar mais no aprimoramento de parâmetros técnicos de exame. Preliminarmente, compreender as principais discussões e questões que envolvem a moral no campo da filosofia, da ética, do direito e de outras ciências é um passo que pode resultar em ganhos valiosos na hora de se discutir e decidir se uma marca incide ou não na proibição do inciso III, do artigo 124, da LPI. É a humilde dica que deixamos para acadêmicos e para os examinadores de marcas do INPI.

\section{Referências Bibliográficas}

distinguir serviços de bar, bufê, café e restaurantes. Os dois sinais apresentam em sua composição a imagem de um peru (animal) e aludem a uma gíria. 
ARNOLDI, Paulo Roberto Colombo; ADOURIAN, Eva Haig. A Revolução das Marcas: do direito industrial à propriedade intelectual. Revista de Direito Privado. [s.1], n. 16, p. 225-259, out/dez, 2003.

CERQUEIRA, João da Gama. Tratado da Propriedade Industrial. Vol. 2. São Paulo: Revista dos Tribunais, 1982.

DE OLIVEIRA, Maurício Lopes. Marca: objeto do desejo. Revista da Associação Brasileira da Propriedade Intelectual - ABPI. São Paulo, vol. 24, p. 27-30, set/out. 1996.

\section{Direito de}

Marcas. Rio de Janeiro: Editora Lumen Juris, 2004.

GUGGENHEIM, Jack Achiezer. Renaming the Redskins (and the Florida State seminoles?): the Trademark Registration Decision and Alternative Remedies. Florida State University Law Review, $\quad \mathrm{n}^{\circ} \quad 287, \quad$ 1999. Disponível em: <http://diginole.lib.fsu.edu/fsulr/vol27/iss1/ 10>. Acesso em 20 de fevereiro de 2015 .

INPI. Manual de Marcas. Portal do INPI. Disponível em: <http://manualdemarcas.inpi.gov.br/>.

Acesso em 12 de agosto de 2015.

KLEIN, Naomi. Sem Logo. A Tirania das Marcas em um Mundo Vendido. Rio de Janeiro: Record, 2002.

LaLONDE, Anne Gilson \& GILSON, Jerome. Trademarks Laid Bare: Marks that May Be Scandalous or Imoral. The Trademark Reporter, vol. 101, $\mathrm{n}^{\circ}$ 5. INTA, septemberoctober, 2011. Disponível em: $<$ http://www.brinksgilson.com/files/article trade marks_laid bare gilsonlalonde_2011.pdf>

Acesso em 20 de fevereiro de 2015.

MARTINS. W. Produzindo no escuro políticas para a indústria cinematográfica e o papel da censura (1964-1988). Rio de Janeiro: autografia, 2016.

NUNES, Gílson. Marca é o Maior Ativo das Empresas na Economia. Revista da Associação Brasileira da Propriedade Intelectual - ABPI. São Paulo, vol. 63, p. 68-69, mar/abr. 2003. POULlaUd-DULIAN, Frédéric. Propriété Intellectuelle. La Propriété Industrielle. Paris: Economica, 2011. 
SOARES, José Carlos Tinoco. Tratado da

Propriedade Industrial: marcas e congêneres.

Vols. I e II. São Paulo: Editora Jurídica Brasileira, 2003.

TIMES. Judge Orders Cancellation of Washington Redsin`s Federal Trademark.

Disponível em: <http://time.com/3949330/washington-redskins-

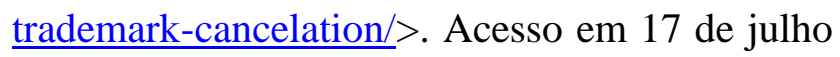
de 2015. 